\title{
Picoeukaryotic Diversity and Distribution in the Reservoir Ecological System
}

\author{
Yuntao $\mathrm{Li}^{1,2}$, Kesai Liu ${ }^{1}$, Yuexin $\mathrm{Xu}^{1}$, Xixia Liu ${ }^{1}$, Jianjun $\mathrm{Hou}^{1, *}$, Yonghong $\mathrm{Bi}^{3, *}$,
}

${ }^{1}$ Hubei Normal University, Hubei Key Laboratory of Edible Wild Plants Conservation and Utilization, Huangshi 435002, China.

${ }^{2}$ Bengbu University, Bengbu 233030, China.

${ }^{3}$ The Chinese Academy of Sciences, State Key Laboratory of Freshwater Ecology and Biotechnology, Institute of HydrobiologyWuhan 430072, China.

\section{Article History}

Received 21 May 2019

Accepted 25 Jun 2019

First Online 1 July 2019

\section{Corresponding Author}

Tel.: +867146511613

E-mail: jjhou@hbnu.edu.cn

\section{Keywords}

Picoeukaryotes

Microbial Diversity

18S rDNA

The Three Gorges Reservoir

\begin{abstract}
The Three Gorges Reservoir of China is a remarkable water conservancy project. It is thus significant to study the dynamics of the reservoir ecological system and plankton distribution. In this study, we used Sanger-based sequencing of the clone libraries of the $18 \mathrm{~S}$ rRNA gene to analyze the picoeukaryotic diversity (size class 0.7-5 $\mu \mathrm{m}$ ) from two sampling sites along the Three Gorges Reservoir during the four seasons in 2013. The community investigated by our approach was dominated by three main phyla, Cryptophyta (30.88\% of clones), Chlorophyta (9.6\%), and Bacillariophyta (8.7\%). In spring, the parasitic population of chytrids in the reservoir is high and may limit the abundance of diatoms. Moreover, the spatial pattern prevails over temporal variability in picoeukaryotic community structure of the Three Gorges Reservoir. Further analyses show that the spatial differences in community structure are mainly caused by the variability of non-dominant phyla. This leads to the hypothesis that the injection of tributaries will have a certain effect on the plankton community structure of the main stream of the Three Gorges Reservoir.
\end{abstract}

\section{Introduction}

Picoeukaryotes are found in marine and freshwater ecosystems and contribute significantly to autotrophic communities (Caron, Countway, Jones, Kim, \& Schnetzer, 2012; Tamm, Laas, Freiberg, Nõges, \& Nõges, 2018). During the past few years, various molecular techniques have been used to explore the picoeukaryote diversity. Currently, there are some reports about picoeukaryotes in a variety of aquatic environment. The water bodies involved in these studies include Oceans (Choi et al., 2016), freshwater lakes (Lepère, Domaizon, Hugoni, Vellet, \& Debroas, 2016), rivers (Contant \& Pick, 2013), and shallow freshwater systems such as ponds (Simon et al., 2015).

A river reservoir stores water, which may stay there for long periods, giving it a specific ecological niche. While the environmental problems associated with these reservoir areas have attracted general attention of scientists (Guo, Wang, Xu, \& Xia, 2011; Dai, Mao, Jiang, \& Wang, 2013), there have been few studies on the picoeukaryote diversity in the reservoirs so far. The Three Gorges Reservoir of China is a large water control project. After the reservoir began storing water in 2003, water property of the Three Gorges Reservoir has dramatically changed, accompanied by a considerable change in community structure of aquatic organism (Han et al., 2015). Likewise, the structural and functional responses of picoeukaryotes to environmental changes caused by the Three Gorge Dam remains to be elucidated in detail.

At present, several studies on plankton were carried out in the Three Gorges Reservoir (Zhang et al., 2006; Deng et al., 2009; Wang, Qi, Chen, \& Hu, 2012). 
However, study about the picoeukaryotic diversity of the Three Gorges Reservoir is still absent. This study aimed at exploring the composition of picoeukaryote communities in the Three Gorges Reservoir during different seasons using Sanger-based sequencing of $18 \mathrm{~S}$ rDNA clone libraries. The aims of this study include: (i) examination of the composition and distribution of picoeukaryotes in a reservoir; (ii) analysis of the temporal and spatial dynamics of the picoeukaryote diversity.

\section{Materials and Methods}

\section{Sample Collection and Environmental Data}

The study was performed in areas of the Three Gorges Reservoir which located on the Yangtze River of China. Water samples were collected from the Three Gorges Reservoir in April (spring), August (summer), October (autumn) and December (winter) of 2013 at two sites (CJ01 and CJ07) (Figure 1). The linear distance between the $\mathrm{CJO} 1$ and $\mathrm{CJ07}$ sample sites was approximately 32.5 kilometres. The Three Gorges Reservoir is a canyon-shaped, typical river-type reservoir. The water body type of these two sites were different. CJ07 site is in river-type region and the CJ01 site is in transition-type region (Zheng, Zhang, Fu, \& Zhang, 2006).

Water sample were collected at a depth of $0.5 \mathrm{~m}$ beneath the water surface using 5-L sampler and prefiltered through a $5 \mu \mathrm{m}$ pore-size polycarbonate filters (Millipore) followed by filtration onto GF/F filters (0.7 $\mu \mathrm{m}$, Whatman) for molecular analyses. Filters were flash-frozen and stored at $-80^{\circ} \mathrm{C}$ until analysis.

Some physical and chemical factors, water temperature (WT), dissolved oxygen (DO), $\mathrm{pH}$ and turbidity were measured in situ. Chemical Oxygen Demand (COD, potassium permanganate method), concentrations of total nitrogen (TN, alkaline potassium persulfate method), orthophosphate $\left(\mathrm{P}^{-} \mathrm{PO}_{4}\right.$, ascorbic acid molybdenum blue method), nitrate $\left(\mathrm{N}-\mathrm{NO}_{3}\right.$, cadmium reduction method), total phosphorus (TP, ammonium molybdate method), Oxidation-Reduction Potential (ORP, potentiometric method), and ammonium ( $\mathrm{N}-\mathrm{NH}_{4}$, Nessler reagent colorimetry) were measured following the methods of Huang et al (Huang, Chen, \& Cai, 1999).

\section{Clone library Construction}

DNA was extracted from filters using a previously described method (Ganesh, Parris, DeLong, \& Stewart, 2014). Near full-length $18 S$ rDNA fragments were amplified by PCR using the eukaryotic-specific primers Euk328f (5-ACCTGGTTGATCCTGCCAG-3) and Euk329r (5-TGATCCTTCYGCAGGTTCAC-3) (Romari \& Vaulot, 2004). The PCR program for amplification was: $94^{\circ} \mathrm{C}$ for $2 \mathrm{~min}$; followed by 35 cycles of $94^{\circ} \mathrm{C}$ for $30 \mathrm{~s}, 55^{\circ} \mathrm{C}$ for 45 $\mathrm{s}$, extension at $72^{\circ} \mathrm{C}$ for $2 \mathrm{~min}$; followed a final extension by $8 \mathrm{~min}$ at $72^{\circ} \mathrm{C}$. Amplicons were purified using the Gel Extraction Kit (Tiangen biotech, China). 18S rDNA clone libraries were constructed using the PGEM $^{\circledR}-T$ Easy Vector Systems (Promega) following the instructions provided by the manufacturer.

\section{Amplified Ribosomal DNA Restriction Analysis (ARDRA) and Sequencing}

Positive clones from each library were screened by PCR and positive PCR product was digested with Haell (Fermentas). Clones with the same restriction fragment length polymorphism (RFLP) pattern were grouped and considered as the same operational taxonomic unit (OTU). Representative clone from different RFLP pattern were randomly selected and partially sequenced (Majorbio, China). Colonies were sequenced using the Euk528F primer (5'-GCGGTAATTCCAGCTCCAA-3') (Elwood, Olsen, \& Sogin, 1985). All obtained sequences
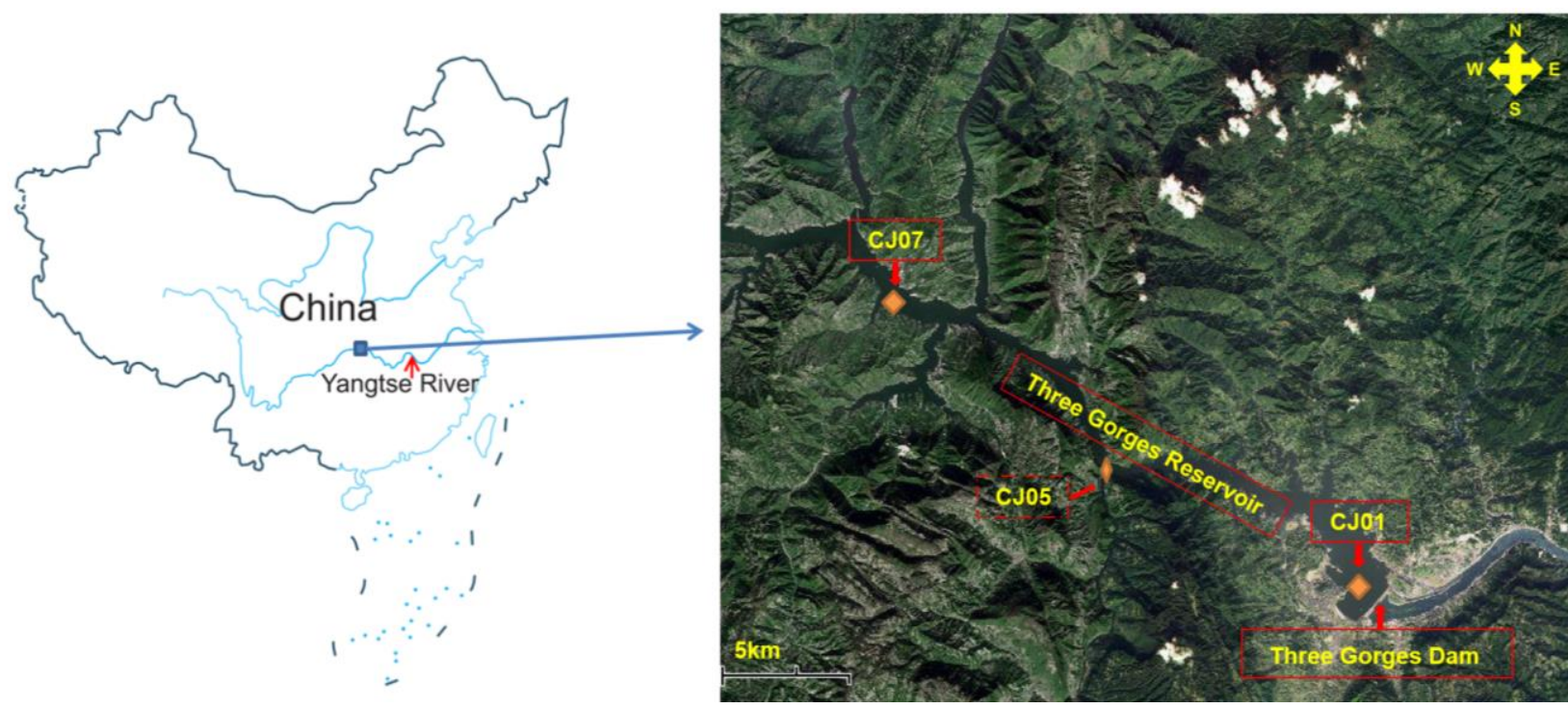

Figure 1. Map of the study area and sampling site. The sampling sites of this study are CJ01 and CJ07. 
were checked for chimerical structures using the CHECKCHIMERA program on the Ribosomal Database Project (http://rdp.cme.msu.edu/html/). All non-chimeric sequences were aligned using the online automatic SILVA Incremental Aligner SINA v1.2.11 (http://www.arb-silva.de/aligner/) to assign sequences to taxonomic groups based on sequence similarity.

\section{Statistical Analyses}

The differences of environmental factors and diversity indexes among the four seasons or two sample sites were analysed using the non-parametric MannWhitney U-tests (two groups) or Kruskal-Wallis (more groups) tests. These tests analysis was performed using SPSS software (version 24, IBM). Based on the result of ARDRA analysis, some diversity indexes (ShannonWiener and Pileos's equitability) were calculated based on OTUs relative abundance using the software PAST 3.0. Variations in picoeukaryotic community structure were characterized in a principal coordinate analysis (PCOA) based on OTUs relative abundance using BrayCurtis distances. The significance of the observed differences was determined by permutational multivariate analysis of variance (PERMANOVA) based on Bray-Curtis distance using 9999 permutations. Similarity percentage analysis (SIMPER) was used to assessing which taxa are primarily responsible for an observed difference between groups. PCoA, PERMANOVA and SIMPER were carried out using $R$ package vegan. Taxa that differed significantly $(q<0.05)$ for two groups were identified using White's nonparametric t-test with Storey's multiple testing correction in the Statistical Analyses of Metagenomic Profiles (STAMP) software version 2.1 (Parks, Tyson, Hugenholtz, \& Beiko, 2014). A canonical correlation analysis (CCA) was applied in order to graphically correlate the multidimensional variation of a set of environmental and biological variables using vegan package of R. To identify environmental factors that significantly correlate with picoeukaryotic communities, an alternative CCA model was constructed using the step function in $\mathrm{R}$ and Akaike's information criterion (AIC).

\section{Results}

\section{Environmental Characterization}

The physicochemical parameters of water samples were present in Figure 2. Water temperature range from 13.9 to 26.9 centigrade in the region. There was no significant difference in the 11 parameters between the CJ01 and CJ07 sites (Mann-Whitney U-tests, all P>0.5). Moreover, these parameters did not significantly differ across the four seasons (Kruskal-Wallis tests, all P>0.08).

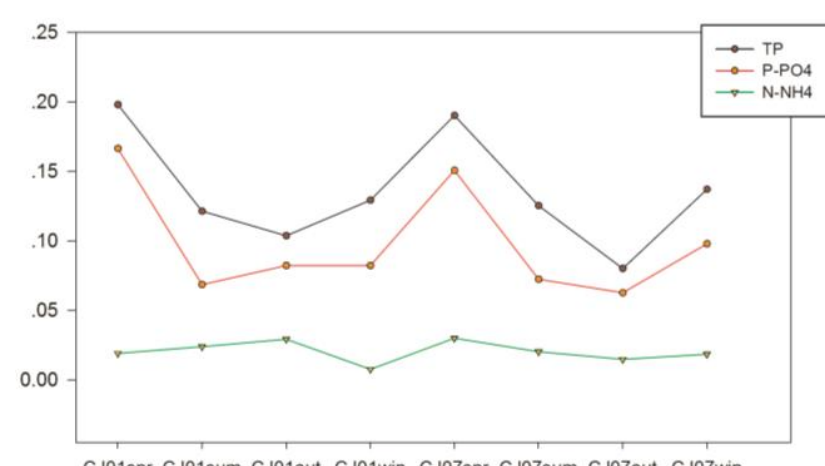

CJ01spr CJ01sum CJ01aut CJ01win CJ07spr CJ07sum CJ07aut CJ07win sample

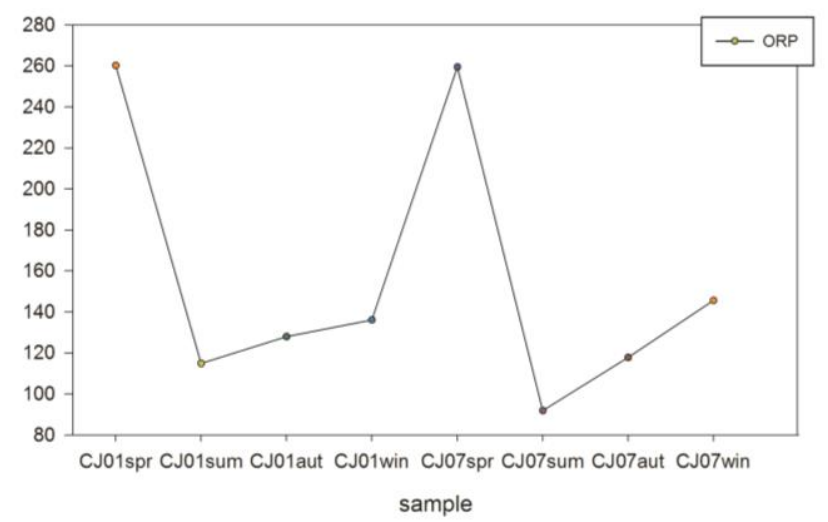

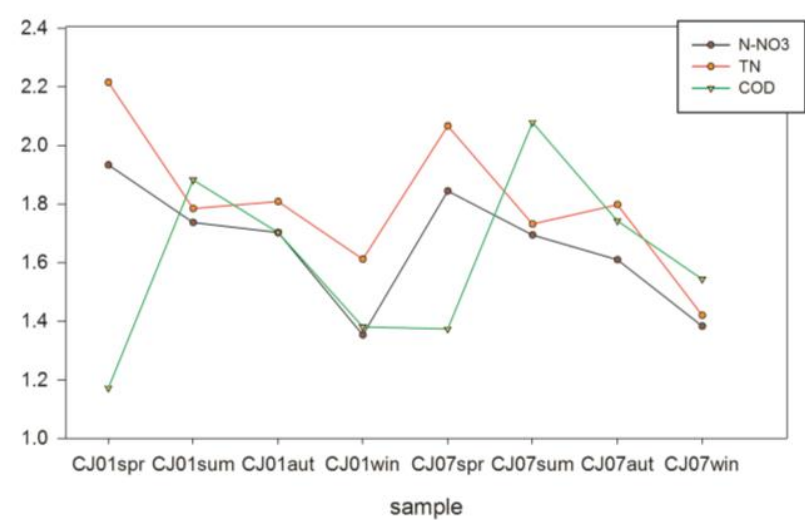

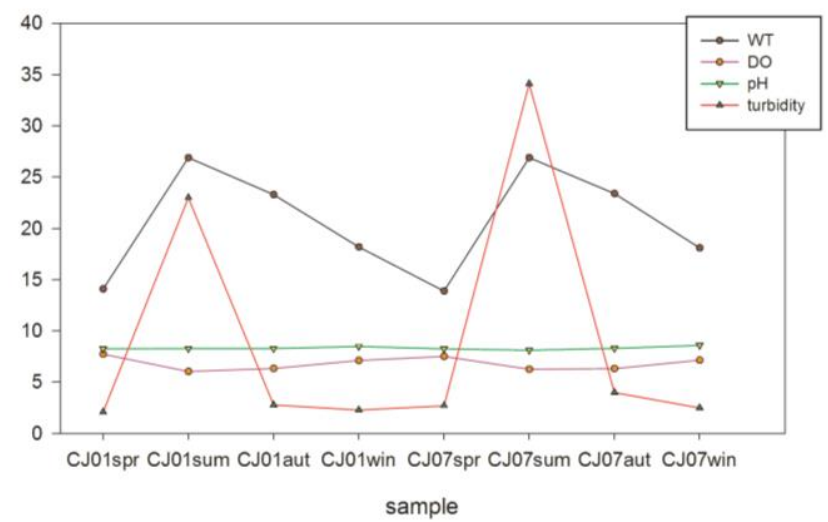

Figure 2. Map of variation of environmental factors. Spr: spring; sum: summer; aut: autumn; win: winter. WT: water temperature; DO: dissolved oxygen; TN: total nitrogen; P-PO4: orthophosphate; N-NO3: nitrate; TP: total phosphorus; N-NH4: ammonium; COD: chemical oxygen demand; ORP: oxidation-reduction potential. 


\section{Coverage and Diversity of Clone Libraries}

Eight clone libraries in all were constructed and a total of 705 positive clones, approximately 64-104 clones from each clone library, were analyzed. These clones clustered into 166 OTUs. CJ01 and CJ07 sites shared 28 OTUs, but only 2 OTUs were recorded throughout the year in the Three Gorges Reservoir (Figure 3). The coverage of the respective libraries ranged from $74 \%$ to $91 \%$ (Table 1 ). The diversity indices (Shannon-Wiener and equitability) did not significantly differ between CJ01 and CJ07 sites (all P>0.5, MannWhitney U-tests). Meanwhile, no significant difference of the diversity indices was observed between seasons (Kruskal-Wallis tests, all $\mathrm{P}>0.1$ ). The Shannon-Wiener index was lowest in winter during the year (Table 1).

\section{Community Composition, Similarity, and Diversity}

A total of 145 high-quality sequences were obtained after quality control process. Based on the phylogenetic analyses, 14 taxa at the level of phylum were identified. Furthermore, there were Raphidophyceae, Bicosoecida, and MAST-3. A significant number of sequences (38 sequences) in these libraries did not show a close affiliation with any known class of organisms (Table 2).

In this study, all the sequences of Cryptophyta belonged to class Cryptophyceae. Among Cryptophyta, Cryptomonas and Teleaulax were the most abundant taxa. The sequences affiliated with Chlorophyta belonged to two taxa, Trebouxiophyceae and Chlorophyceae. Within Chlorophyta, Chlorophyceae
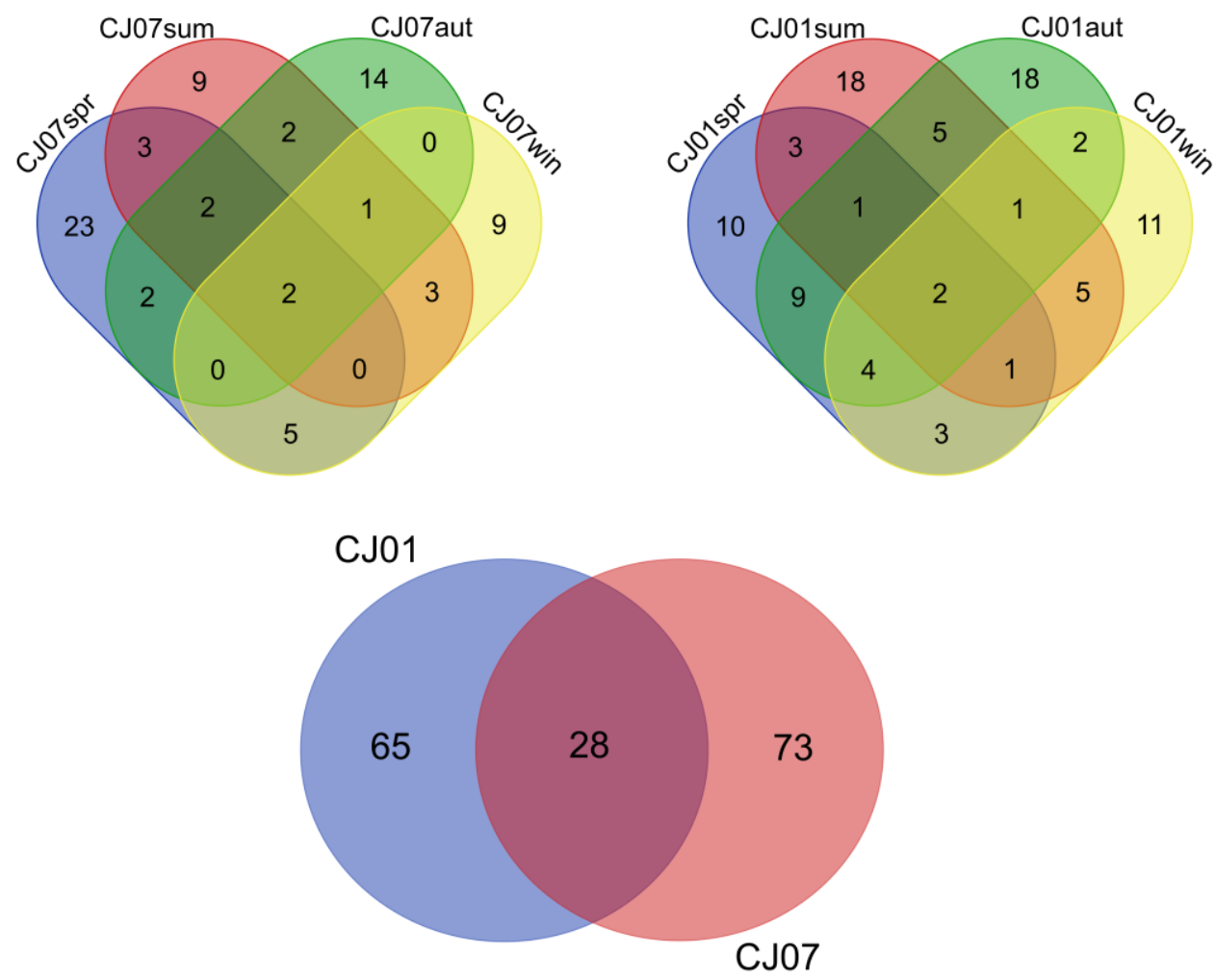

Figure 3. Venn diagrams showing shared and unique season and sample sites OTUs based on clone libraries.

Table 1. Summary of amplified ribosomal DNA restriction analysis of the eight clone libraries

\begin{tabular}{|c|c|c|c|c|c|}
\hline Season & Sample sites & $\begin{array}{l}\text { No. of RFLP } \\
\text { types }\end{array}$ & Coverage & Shannon-Wiener & Equitability (J') \\
\hline \multirow{2}{*}{ Spring } & CJ01 & 33 & $90.63 \%$ & 3.11 & 0.89 \\
\hline & $\mathrm{CJ} 07$ & 37 & $82.69 \%$ & 3.20 & 0.89 \\
\hline \multirow[t]{2}{*}{ Summer } & CJ01 & 36 & $87.10 \%$ & 3.29 & 0.92 \\
\hline & CJ07 & 22 & $78.22 \%$ & 3.22 & 0.88 \\
\hline \multirow[t]{2}{*}{ Autumn } & CJ01 & 42 & $74.12 \%$ & 3.48 & 0.93 \\
\hline & CJ07 & 23 & $82.81 \%$ & 3.17 & 0.95 \\
\hline \multirow{2}{*}{ Winter } & CJ01 & 29 & $83.33 \%$ & 2.84 & 0.84 \\
\hline & $\mathrm{CJO7}$ & 20 & $91.03 \%$ & 2.92 & 0.92 \\
\hline
\end{tabular}


Table 2. Numbers of sequences identified in phylogenetic groups in the Three Gorges Reservoir

\begin{tabular}{|c|c|c|c|c|c|}
\hline Super Group & Phylum & Division & & & Sequence number \\
\hline & Cryptophyta & Cryptophyceae & & & 36 \\
\hline & & & Cryptomonadales & & 20 \\
\hline & & & & Cryptomonas & 10 \\
\hline & & & & Teleaulax & 10 \\
\hline & & & Kathablepharidae & & 3 \\
\hline & & & & Katablepharis & 1 \\
\hline & & & & uncultured & 2 \\
\hline & & & P1-31 & & 11 \\
\hline \multirow[t]{6}{*}{ Archaeplastida } & Chlorophyta & & & & 14 \\
\hline & & Trebouxiophyceae & & & 2 \\
\hline & & Chlorophyceae & & & 12 \\
\hline & & & Chlamydomonas & & 3 \\
\hline & & & Nephroselmis & & 1 \\
\hline & & & Hafniomonas & & 1 \\
\hline \multirow[t]{12}{*}{ Alveolata } & Ciliophora & & & & 12 \\
\hline & & Spirotrichea & & & 5 \\
\hline & & & Hypotrichia & & 2 \\
\hline & & & uncultured & & 3 \\
\hline & & Litostomatea & & & 2 \\
\hline & & & Haptoria & & 1 \\
\hline & & Prostomatea & & & 2 \\
\hline & & & Cryptocaryon & & 2 \\
\hline & Myzozoa & & & & 1 \\
\hline & Miozoa & & & & 2 \\
\hline & & Gymnodiniphycidae & & & 1 \\
\hline & & Perkinsidae & & & 1 \\
\hline \multirow[t]{9}{*}{ Stramenopiles } & Bacillariophyta & & & & 13 \\
\hline & & Mediophyceae & & & 8 \\
\hline & & Bacillariophyceae & & & 5 \\
\hline & Ochrophyta & & & & 5 \\
\hline & & Chrysophyceae & & & 2 \\
\hline & & Raphidophyceae & & & 2 \\
\hline & & Dictyochophyceae & & & 1 \\
\hline & Oomycota & & & & 1 \\
\hline & Bicosoecida & & & & 4 \\
\hline MAST-3 & & & & & 1 \\
\hline \multirow[t]{9}{*}{ Opisthokonta } & Cryptomycota & & & & 6 \\
\hline & & LKM11 & & & 6 \\
\hline & Basidiomycota & & & & 6 \\
\hline & & Sporidiobolales & & & 3 \\
\hline & & Malasseziales & & & 2 \\
\hline & Chytridiomycota & & & & 2 \\
\hline & & Chytridiomycetes & & & 1 \\
\hline & Myxomycetes & & & & 1 \\
\hline & Choanozoa & & & & 2 \\
\hline \multirow[t]{3}{*}{ Rhizaria } & Cercozoa & & & & 2 \\
\hline & & Thecofilosea & & & 1 \\
\hline & & Novel Clade 10 & & & 1 \\
\hline Unclassified & & & & & 38 \\
\hline
\end{tabular}

was found to be in majority. The sequences matching that of phylum Ciliophora were grouped into three taxa: Spirotrichea, Litostomatea, and Prostomatea. The most abundant Ciliophora was class Spirotrichea. The sequences matching phylum Bacillariophyta affiliated with taxa Mediophyceae and Bacillariophyceae.

In the Three Gorges Reservoir, Cryptophyta was found to be the dominant phyla, followed by Chlorophyta, Bacillariophyta, and Ciliophora (Figure 4). Moreover, some phyla were found to be dominant in a given season. The phyla Cryptomycota and Miozoa were dominant in spring and winter, respectively. Additionally, an uneven distribution of picoeukaryotic plankton was observed. While the abundance of most phyla changed with the seasons (Figure 4), some phyla showing significant seasonal variations (Figure 5). Bacillariophyta were observed to be in significantly higher relative abundance in summer than in autumn (White's non-parametric t-test, $q<0.01$ ). Likewise, Cercozoa varied significantly between autumn and winter (White's non-parametric t-test, $q<0.01$ ) (Figure 5).

The results of PCoA showed that principal components 1 and 2 accounted for $40.55 \%$ of the total sample variability $(21.38 \%$ and $19.17 \%$ for PC1 and PC2, respectively) (Figure 6). A difference between samples from $\mathrm{CJO} 1$ and $\mathrm{CJO} 7$ sites was detected in the PCoA (Figure 6), and this difference was further confirmed to be significant $(p=0.0254)$ through PERMANOVA. In contrast, there was no significant difference in the 

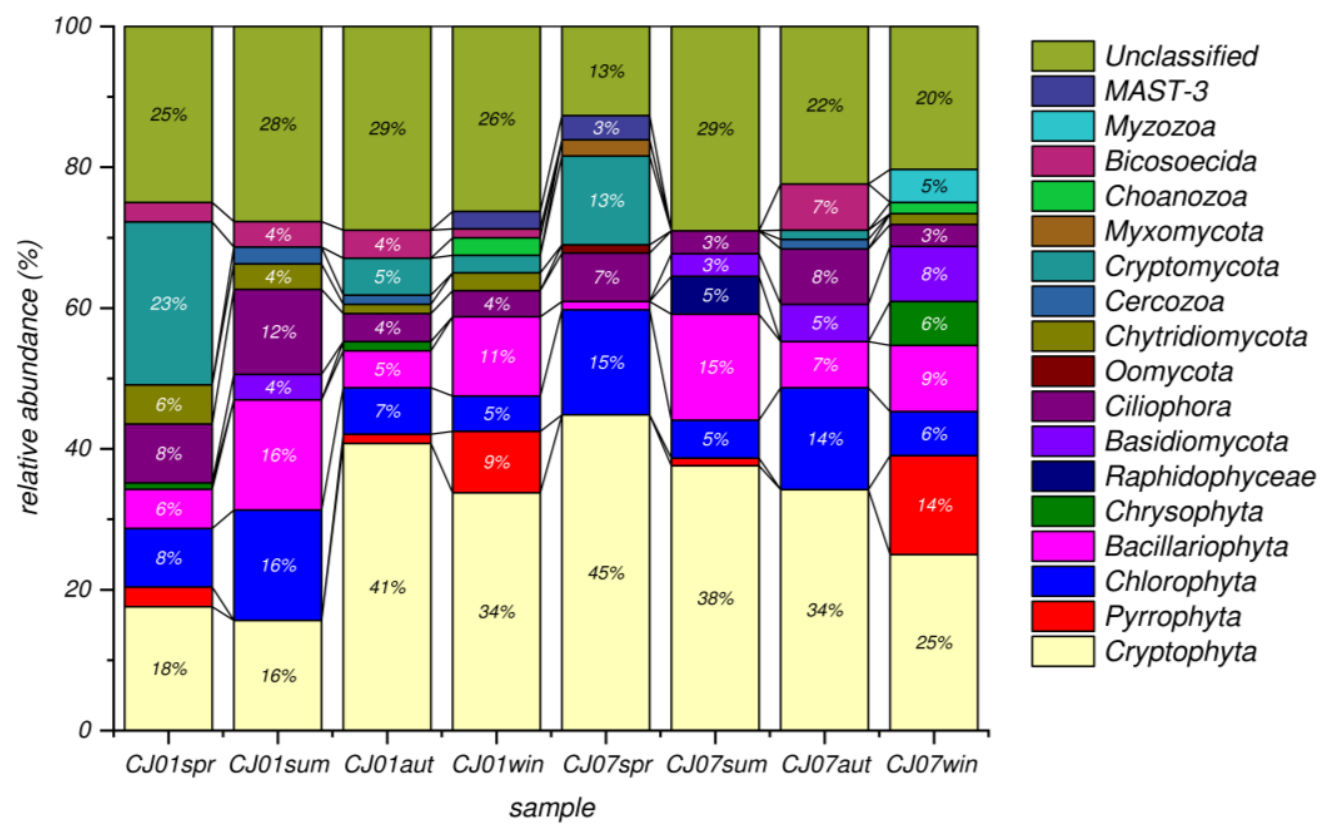

Figure 4. Community compositions at each sampling site.
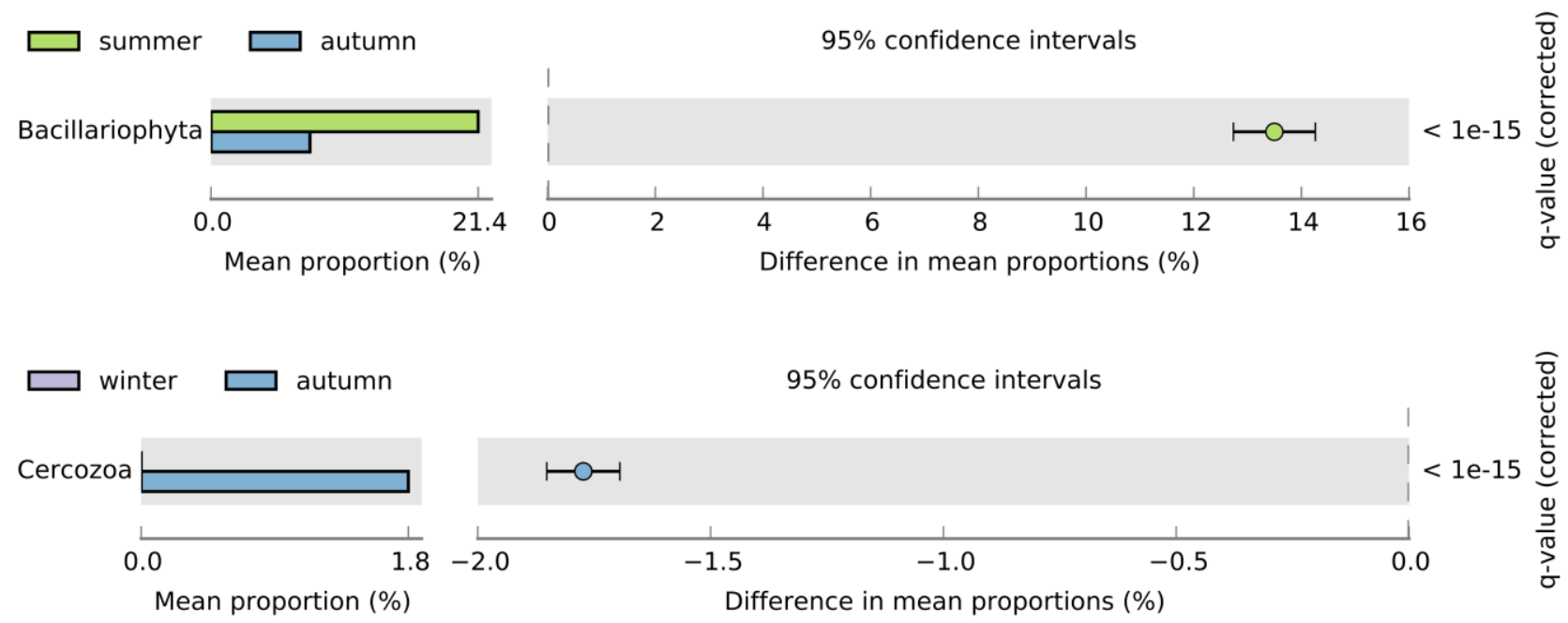

Figure 5. Phyla that were significantly different between two seasons.

microbial community structure between season samples $(p=0.1785)$. This indicates that a spatial pattern prevails over temporal variability in picoeukaryotic community structure of the Three Gorges Reservoir. Moreover, SIMPER analysis showed that the spatial differences in community structure were are mainly caused by the variability of non-dominant phyla. The spatial differences were largely contributed by phyla Bicosoecida (13.06\%), Chytridiomycota (12.36\%), Basidiomycota (11.14\%), and Cercozoa (10.84\%) (Table 3).

\section{Temporal and Spatial Dynamics of Functional Groups}

Picoeukaryote detected in this study was roughly divided into three functional groups: primary producers, free-living heterotrophs, and parasites. Primary producers contained mixotrophs and obligate phototrophs, free-living heterotrophs comprised osmotrophs or phagotrophic predators. And finally, parasites included Chytridiomycota, Oomycota, and Cryptomycota. The percentage of functional groups varied in different sample sites (Figure 7). The primary producers were seen to occupy the largest relative abundance among the eight samples and reached the highest proportion in autumn at the CJ01 site, and in summer at the $\mathrm{CJ07}$ site. Throughout the year, the relative abundance of parasites was the lowest except in spring.

\section{Relationship between Communities and Environmental Variables}

CCA was performed using the relative abundance data for the mentioned taxa and used to determine how environmental parameters influenced the 


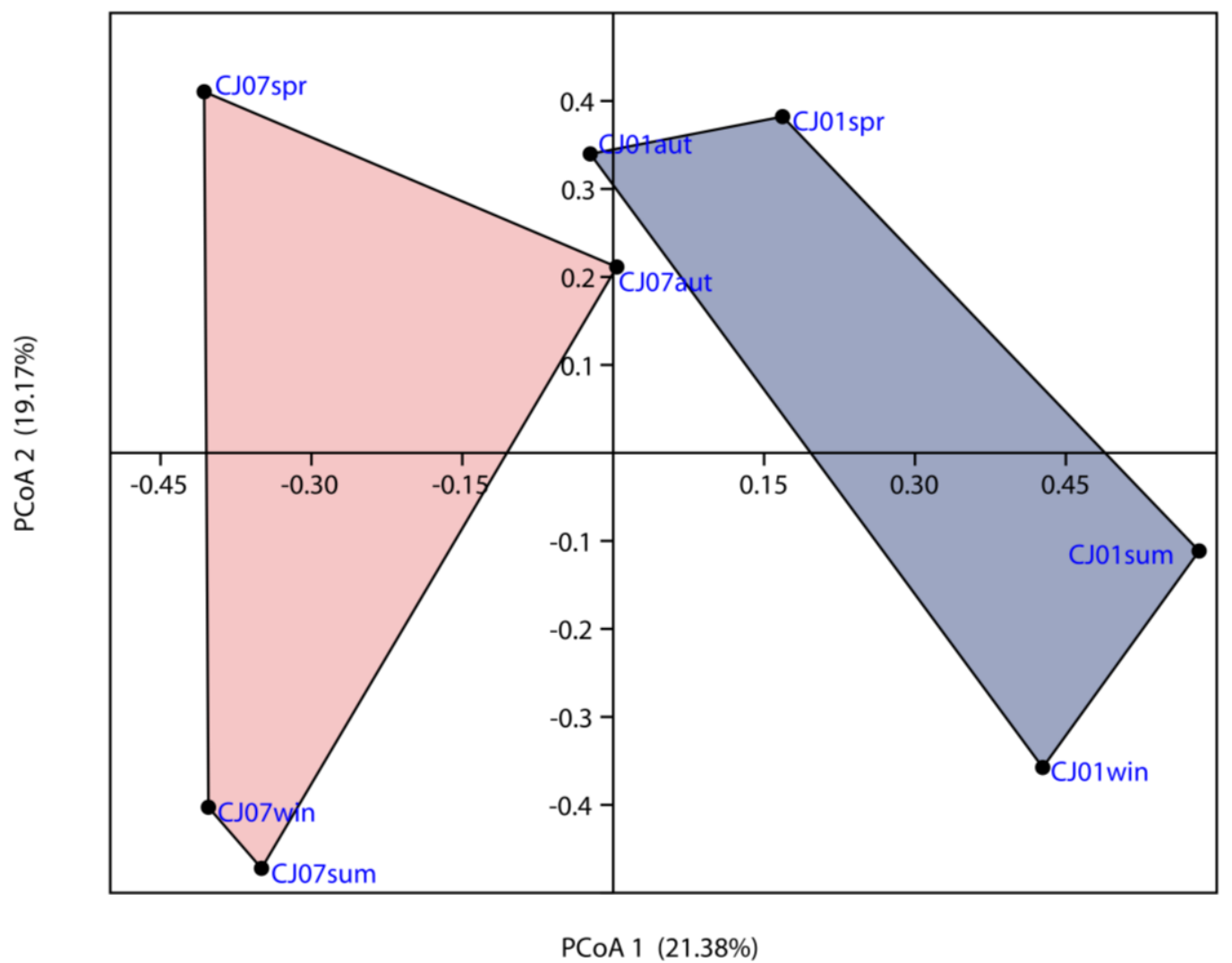

Figure 6. Principal coordinate analysis (PCOA) of picoeukaryotic communities based on the Bray-Curtis similarity between samples.

Table 3. Results of the similarity percentage (SIMPER) analysis among the two sites

\begin{tabular}{lccccc}
\hline Taxon & Av. dissim & Contrib. \% & Cumulative \% & Mean 1 & Mean 2 \\
\hline Bicosoecida & 5.325 & 13.06 & 13.06 & 2.5 & $1.61 \mathrm{E}+09$ \\
Chytridiomycota & 5.037 & 12.36 & 25.42 & 3 & $1.61 \mathrm{E}+09$ \\
Basidiomycota & 4.542 & 11.14 & 36.56 & $1.61 \mathrm{E}+09$ & $5.37 \mathrm{E}+08$ \\
Cercozoa & 4.417 & 10.84 & 47.4 & $5.37 \mathrm{E}+08$ & $1.61 \mathrm{E}+09$ \\
Cryptomycota & 3.684 & 9.038 & 56.44 & 7.75 & $1.07 \mathrm{E}+09$ \\
Ochrophyta & 3.561 & 8.737 & 65.17 & $1.07 \mathrm{E}+09$ & $1.61 \mathrm{E}+09$ \\
Miozoa & 3.461 & 8.49 & 73.66 & $5.37 \mathrm{E}+08$ & $1.07 \mathrm{E}+09$ \\
Choanozoa & 2.802 & 6.875 & 80.54 & $1.61 \mathrm{E}+09$ & $1.61 \mathrm{E}+09$ \\
MAST-3 & 2.608 & 6.398 & 86.94 & $1.61 \mathrm{E}+09$ & $1.61 \mathrm{E}+09$ \\
Myzozoa & 2.043 & 5.013 & 91.95 & $2.15 \mathrm{E}+09$ & $1.61 \mathrm{E}+09$ \\
Myxomycota & 1.641 & 4.025 & 95.98 & $2.15 \mathrm{E}+09$ & $1.61 \mathrm{E}+09$ \\
Raphidophyceae & 1.641 & 4.025 & 100 & $2.15 \mathrm{E}+09$ & $1.61 \mathrm{E}+09$ \\
Cryptophyta & $3.49 \mathrm{E}-08$ & $8.55 \mathrm{E}-08$ & 100 & 22.5 & 29 \\
Unclassified & $2.71 \mathrm{E}-08$ & $6.65 \mathrm{E}-08$ & 100 & 23.3 & 17 \\
Bacillariophyta & $1.55 \mathrm{E}-08$ & $3.81 \mathrm{E}-08$ & 100 & 8 & 6.5 \\
Chlorophyta & $1.35 \mathrm{E}-08$ & $3.31 \mathrm{E}-08$ & 100 & 7.75 & 8.25 \\
Ciliophora & $1.15 \mathrm{E}-08$ & $2.83 \mathrm{E}-08$ & 100 & 6.25 & 0 \\
Oomycota & $7.64 \mathrm{E}-10$ & $1.87 \mathrm{E}-09$ & 100 & & 0.25 \\
\hline
\end{tabular}

picoeukaryotic community structures. TN and WT were selected for further analysis (Figure 8). In the CCA, all variables together explained $49.5 \%$ of variance in taxonomic data. According to the gradient plot (Figure 8), Ochrophyta and Miozoa were distributed in an area with low TN concentration. Basidiomycota appeared in the area with high WT.

\section{Discussion}

While the previous microscopy based studies have shown the dominance of taxa Bacillariophyta and Chlorophyta in the head region of the Three Gorges Reservoir (Wang et al., 2015), our results show that in pico- particle size, Cryptophyta accounted for the largest 


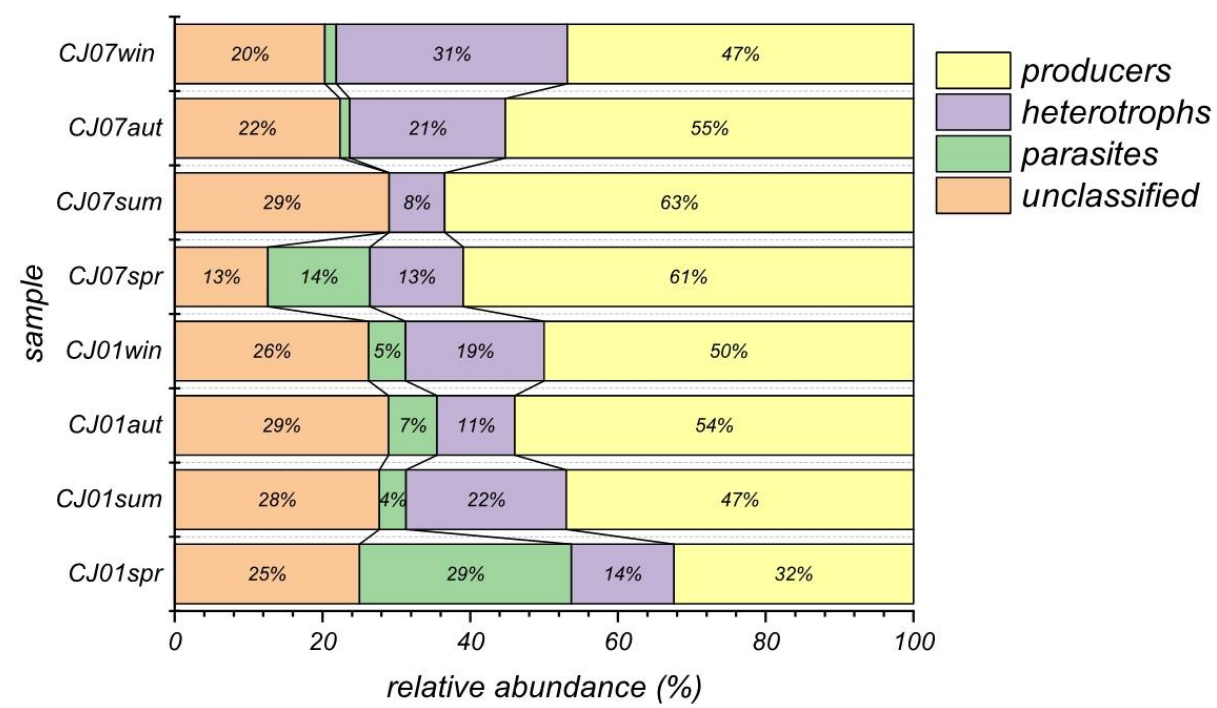

Figure 7. Distribution of parasites, heterotrophs and primary producers in all samples.

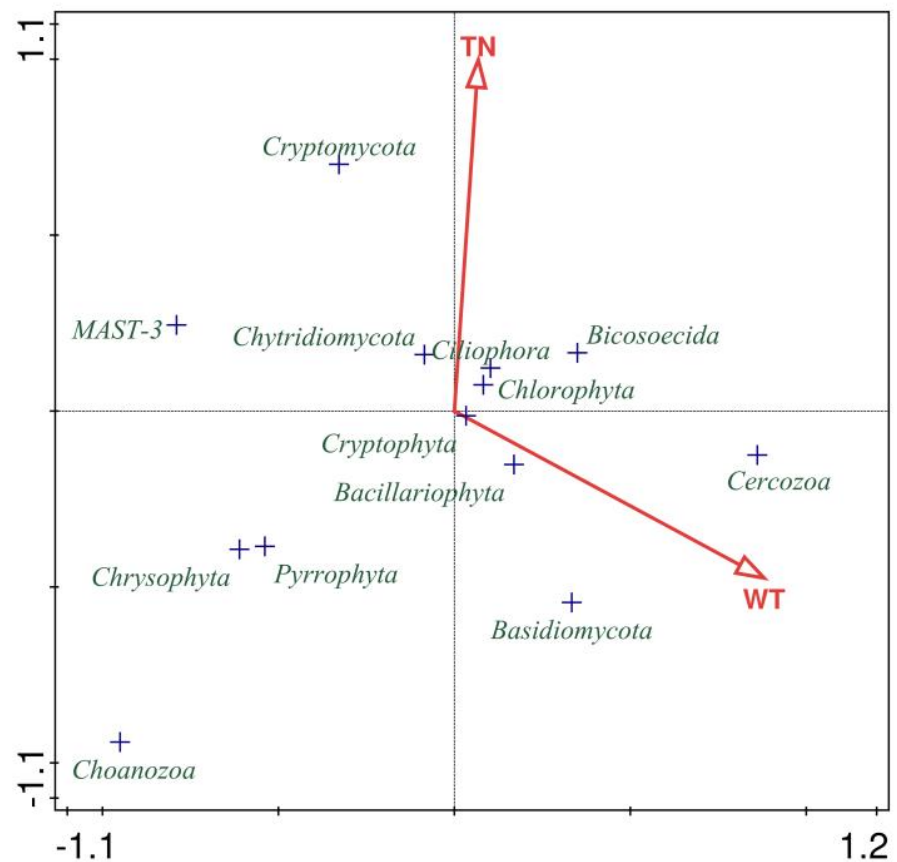

Figure 8. Canonical correspondence analysis (CCA) ordination plot of phyla and environmental parameters. WT: water temperature; TN: total nitrogen.

proportion of relative abundance and followed by Chlorophyta. Although Cryptophytes are generally nanoplankton, some studies based high throughput sequencing have shown that Cryptophyta is dominant in pico- particle size in freshwater systems (Simon et al. 2015). This suggests that under different particle sizes the community structure of algae also differ, in accordance with the results of other studies (Bazin et al., 2014). Some studies compare molecular and microscopy methods (Xiao et al. 2014). Their study indicates that taxa compositions detected by light microscopy and molecular methods do not always match. Molecular methods detected rarer species and picoplankton than light microscopy.
In this survey, Cryptomycota showed an obvious seasonality and reached the highest percentage in spring (23\% in the CJ01 site) (Figure 4). All these Cryptomycota particularly belonged to LKM11. Cryptomycota are parasitic in chytrid, Blastocladiomycota, Oomycota, Basidiomycota, and the green alga (Gleason et al., 2014; Letcher et al., 2018). So, high abundance of Cryptomycota in spring may affect the phytoplankton community structure. While the diatom abundance generally increases in spring and decreases in summer (Yao, Liu, Li, \& Yang, 2009; Breuer, Janz, Farrelly, \& Ebke, 2017), surprisingly, in this study, the diatoms reached highest relative abundance in summer. Perhaps, one of the explanations may be the 


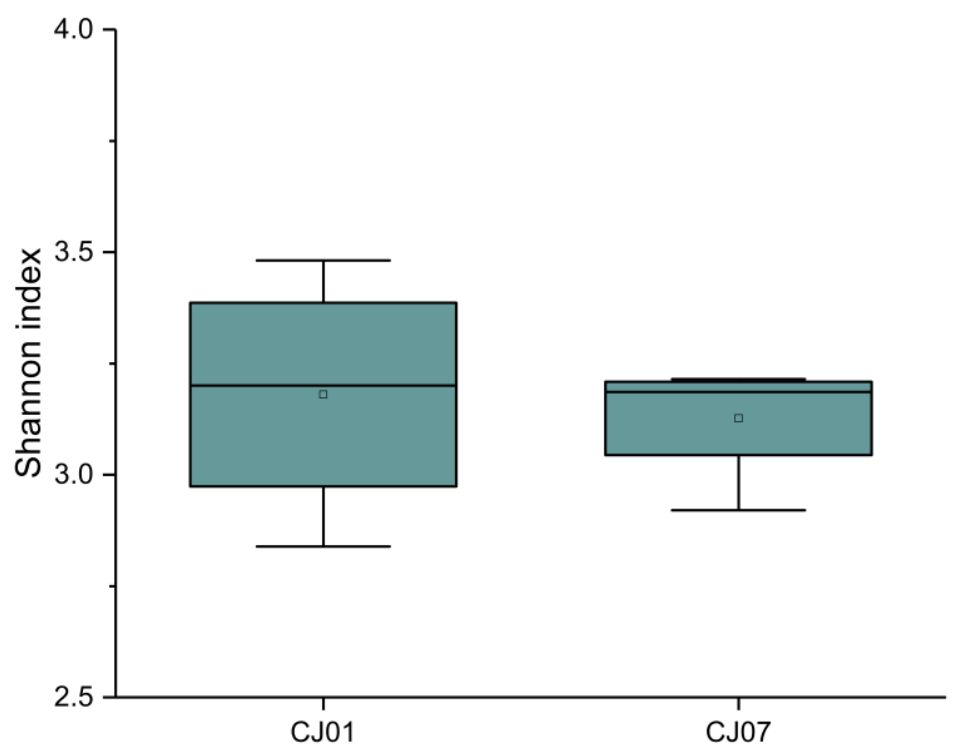

Figure 9. Diversity index plot.

presence of a lot of parasites in spring (Figure 7). In spring, in spite of the number of Cryptomycota is larger, chytrids are still in abundance (Figure 4). Since chytrids can infect multiple diatom species and even kill their hosts (Sime-Ngando, 2012; Gsell, de Senerpont Domis, Verhoeven, van Donk, \& Ibelings, 2013), they are efficient antagonists of bloom-forming phytoplanktons (Gsell et al., 2013). Consequently, the abundance of diatom may be limited by the chytrids.

It was surprising that spatial pattern prevails over temporal variability in picoeukaryotic communities in this survey. However, there was no significant difference in physicochemical factors between the $\mathrm{CJO} 1$ and $\mathrm{CJO} 7$ sites. In contrast, our other study showed that the temporal pattern of picoeukaryotic communities prevails over spatial variability at $\mathrm{CJ} 01$ and $\mathrm{CJ} 05$ sites in the Three Gorges Reservoir (Figure 1) (Hou et al., 2017). This inconsistency may be explained by the following points. First, the Three Gorges Reservoir is a canyonshaped and a typical river-type reservoir. The water flow velocity slows down gradually from the end of reservoir to the front of dam. CJ07 and CJ05 sites are in river-type region, but $\mathrm{CJ} 05$ site closer to the reservoir dam. Some studies showed that the hydraulic retention time was a limiting factor of an increase in plankton in reservoir (Mašín et al., 2003; Moitra \& Leff, 2015). Therefore, this maybe one reason that the picoeukaryotic communities were significantly different between $\mathrm{CJ} 07$ and $\mathrm{CJ} 01$ sites but not significant between $\mathrm{CJO} 5$ and $\mathrm{CJO} 1$ sites. Second, between the $\mathrm{CJO} 1$ and $\mathrm{CJO} 7$ sites, the XiangXi and TongZhuang Rivers flow into the main stream of Three Gorges Reservoir. Previous studies have shown that the plankton composition varies between tributaries and main streams of Three Gorges Reservoir (Wang et al., 2015). Furthermore, the diversity index of reservoir mainstream was lower than that of tributaries (Chen et al., 2009). Additionally, the Shannon index of CJ01 site is higher than that of the CJ07 site (Figure 9). Thus, the injection of tributaries may affect the plankton community structure of the main stream of the Three Gorges Reservoir. Our results may reflect the influence of water velocity on community structure in reservoirs, it also suggests that the injection of tributaries may affect the diversity of the main stream. But these need further verification.

\section{Acknowledgments}

This work was supported by the National Natural Science Foundation of China (41171045), the Research Fund for Science and Technology Inovation Team of University (T201504). We are thankful to Dr. Yonghong $\mathrm{Bi}$ and the Three Gorges reservoir's ecosystem field station for the assistance of sampling.

\section{References}

Bazin, P., Jouenne, F., Friedl T., Deton-Cabanillas, A. F., Roy, B. L., \& Véron, B. (2014). Phytoplankton diversity and community composition along the estuarine gradient of a temperate macrotida ecosystem: combined morphological and molecular approaches. PLOS ONE, 9, e94110. https://doi.org/10.1371/journal.pone.0094110

Breuer, F., Janz, P., Farrelly, E., \& Ebke, K. P. (2017). Environmental and structural factors influencing algal communities in small streams and ditches in central Germany. Journal of Freshwater Ecology, 32, 65-83. https://doi.org/10.1080/02705060.2016.1241954

Caron, D., Countway, P., Jones, A., Kim, D., \& Schnetzer, A. (2012). Marine protistan diversity. Annual Review of Marine Science, 4, 467-493. https://doi.org/10.1146/annurev-marine-120709142802

Chen, Y., Duan, X. B., Liu, S. P., Liu, M. D., Wang, K., \& Chen, D. Q. (2009). Community structure of the phytoplankton in the Three Gorges Reservoir after the third period of sluice. Freshwater Fisheries, 39, 10-15 (in Chinese).

Choi, D. H., An, S. M., Chun, S., Yang, E. C., Selph, K. E., Lee, C. M., \& Noh, J. H. (2016). Dynamic changes in the composition of photosynthetic picoeukaryotes in the northwestern Pacific Ocean revealed by high-throughput 
tag sequencing of plastid 16S rRNA genes. FEMS Microbiology Ecology, 92, fiv170. https://doi.org/10.1093/femsec/fiv170

Contant, J., \& Pick, F. R. (2013). Picophytoplankton during the ice-free season in five temperate-zone rivers. Journal of plankton research, 35, 553-565. https://doi.org/10.1093/plankt/fbt013

Dai, H. C., Mao, J. Q., Jiang, D. G., \& Wang, L. L. (2013). Longitudinal hydrodynamic characteristics in reservoir tributary embayments and effects on algal blooms. PLOS ONE, 8 , e68186. https://doi.org/10.1371/journal.pone.0068186

Deng, W. N., Yu, Y. H., Yan, Q. Y., Song, X. H., Zhang X., \& Chen H. T. (2009). DNA structure analysing of plankton community and physico chmical factors in the Three Gorges Reservoir region. Acta Hydrobiologica Sinica, 2, 324-329 (in Chinese).

Elwood, H. J., Olsen, G. J., \& Sogin, M. L. (1985). The smallsubunit ribosomal RNA gene sequences from the Hypotrichou Ciliates Oxytricha nova and Stylonychia pustulata. Molecular Biology and Evolution, 2, 399-410. https://doi.org/10.1093/oxfordjournals.molbev.a04036 2

Ganesh, S., Parris, D. J., DeLong, E. F., \& Stewart, F. J. (2014). Metagenomic analysis of size-fractionated picoplankton in a marine oxygen minimum zone. The ISME Journal, 8 , 187-211. https://doi.org/10.1038/ismej.2013.144

Gleason, F. H., Lilje, O., Marano, A. V., Sime-Ngando, T., Sullivan, B. K., Kirchmair, M., \& Neuhauser, S. (2014). Ecological functions of zoosporic hyperparasites. Frontiers in Microbiology, 5 , 244. https://doi.org/10.3389/fmicb.2014.00244

Gsell, A. S., de Senerpont Domis, L. N., Verhoeven, K. J., van Donk, E., \& Ibelings, B. W. (2013). Chytrid epidemics may increase genetic diversity of a diatom spring-bloom. The ISME Journal, 7, 2057-2059. https://doi.org/10.1038/ismej.2013.73

Guo, W. X., Wang, H. X., Xu, J. X., \& Xia, Z. Q. (2011). Ecological operation for Three Gorges Reservoir. Water Science and Engineering, 4, 143-156. https://doi.org/10.3882/j.issn.1674-2370.2011.02.003

Han, L. F., Gao, B., Zhou, H. D., Xu, D. Y., Wei, X., \& Gao, L. (2015). The spatial distribution, accumulation and potential source of seldom monitored trace elements in sediments of Three Gorges Reservoir, China. Scientific Reports, 5, 16170. https://doi.org/10.1038/srep16170

Hou, Y. Y., Liu, K. S., Li, S., Liu, X. X., Hou, J. J., \& Li, Y. T. (2017). Study on the biodiversity of ultra micro eukaryotic plankton in the Three Gorges Reservoir. Journal of Wuhan Textile University, 30, 74-80 (in Chinese).

Huang, X. F., Chen, W. M., \& Cai, Q. M. (1999) Survey, observation and analysis of lake ecology. Beijing: China Standard Press (In Chinese).

Lepère, C., Domaizon, I., Hugoni, M., Vellet, A., \& Debroas, D. (2016). Diversity and dynamics of active small microbial eukaryotes in the anoxic zone of a freshwater meromictic lake (Pavin, France). Frontiers in Microbiology, 7, 130. https://doi.org/10.3389/fmicb.2016.00130

Letcher, P. M., Longcore, J. E., James, T. Y., Leite, D. S., Simmons, D. R., \& Powell, M. J. (2018). Morphology, ultrastructure, and molecular phylogeny of Rozella multimorpha, a new species in Cryptomycota. Journal of Eukaryotic Microbiology,

65 , 180-190. https://doi.org/10.1111/jeu.12452

Mašín, M., Jezbera, J., Nedoma, J., Straškrabová, V., Hejzlar J., \& Šimek, K. (2003). Changes in bacterial community composition and microbial activities along the longitudinal axis of two canyon-shaped reservoirs with different inflow loading. Hydrobiologia, 504, 99-113. https://doi.org/10.1023/B:HYDR.0000008512.04563.0b

Moitra, M., \& Leff, L. G. (2015). Bacterial community composition and function along a river to reservoir transition. Hydrobiologia, 747, 201-215. https://doi.org/10.1007/s10750-014-2140-x

Parks, D., Tyson, G. W., Hugenholtz, P., \& Beiko, R. G. (2014). STAMP: statistical analysis of taxonomic and functional profiles. Bioinformatics, 30, 3123-3124. https://doi.org/10.1093/bioinformatics/btu494

Romari, K., \& Vaulot, D. (2004). Composition and temporal variability of picoeukaryote communities at a coastal site of the English Channel from 18S rDNA sequences. Limnology and Oceanography, 49, 784-798. https://doi.org/10.4319/lo.2004.49.3.0784

Sime-Ngando, T. (2012). Phytoplankton chytridiomycosis: fungal parasites of phytoplankton and their imprints on the food web dynamics. Frontiers in Microbiology, 3, 361. https://doi.org/10.3389/fmicb.2012.00361

Simon, M., Jardillier, L., Deschamps, P., Moreira, D., Restoux, G., Bertolino, P., \& López-García, P. (2015). Complex communities of small protists and unexpected occurrence of typical marine lineages in shallow freshwater systems. Environmental Microbiology, 17, 3610-27. https://doi.org/10.1111/1462-2920.12591

Tamm, M., Laas, P., Freiberg, R., Nõges, P., \& Nõges, T. (2018). Parallel assessment of marine autotrophic picoplankton using flow cytometry and chemotaxonomy. Science of the Total Environment, 625, 185-193. https://doi.org/10.1016/j.scitotenv.2017.12.234

Wang, J. Y., Wang, Z. C., Li, C., Ye, S. W., Lian, Y. X., Liu, J. S., Zhang, T. L., \& Li, Z. J. (2015). The spatio-temporal dynamics of phytoplankton community structure in the head region of the Three Gorges Reservoir. Acta Hydroblologica Sinica, 39, 877-884 (in Chinese).

Wang, Y. C., Qi, G. S., Chen, S. S., \& Hu, S. (2012). Research on plankton community in Three Gorges Reservoir during its trial impoundment. Yangtze River, 12, 4-9 (in Chinese).

Xiao, X., Sogge, H., Lagesen, K., Tooming-Klunderud, A., Jakobsen, K. S., Rohrlack, T. (2014). Use of high throughput sequencing and light microscopy show contrasting results in a study of phytoplankton occurrence in a freshwater environment. PLOS ONE, 9, e106510. https://doi.org/10.1371/journal.pone.0106510

Yao, M., Liu, Q., Li, Y. L., \& Yang, X. D. (2009). Seasonal change of planktonic diatom of two small shallow eutrophic lakes in Nanjing. Journal of Lake Science, 21, 693-699 (in Chinese).

Zhang, S., Liu, J. H., Li, L. L., Li S., Xu J., \& Gao J. X. (2006). Distribution features of nutrient and phytoplankton in incipient Three Gorges Reservoir. Chinese Journal of Environmental Science, 6, 1056-1061 (in Chinese).

Zheng, B. H., Zhang, Y., Fu, G., \& Zhang, H. L. (2006). On the assessment standards for nutrition status in the Three Gorge Reservoir. Acta Scientiae Circumstantiae, 26, 1022-1030 (in Chinese). 